\title{
When Is It Cost-effective to Change the Behavior of Health Professionals?
}

\begin{tabular}{l}
\hline James Mason, DPhil \\
\hline Nick Freemantle, PhD \\
\hline Irwin Nazareth, PhD \\
\hline Martin Eccles, MD \\
\hline Andrew Haines, MD \\
\hline Michael Drummond, DPhil \\
\hline
\end{tabular}

$\mathrm{E}$ CONOMIC ANALYSES COMMONLY estimate the incremental costs and benefits of using different treatments on the basis of the best available clinical evidence. They do not include the costs of achieving an appropriate adoption of results by physicians. Important research findings often do not translate automatically into practice ${ }^{1-3}$ while new and wellmarketed products may sometimes achieve a greater market share than merited by their additional costs and benefits. ${ }^{4}$ Consequently, policymakers may have to commit additional resources to influence physician behavior if desirable changes in practice are to be achieved. We provide a framework for exploring the economics of influencing physician behavior. Using 2 examples, our purpose is to distinguish between treatment cost-effectiveness (the incremental costs and benefits of a treatment) and policy cost-effectiveness (combining treatment cost-effectiveness with the cost and magnitude of change achieved by an implementation method).

In England, there is evidence that angiotensin-converting enzyme (ACE) inhibitors are underused in the care of patients with heart failure, ${ }^{5}$ while newer classes of antidepressants have achieved widespread first-line use without demonstrating added value. ${ }^{4}$ Clinical practice guideline development groups, hav-

Because of the workings of health care systems, new, important, and costeffective treatments sometimes do not become routine care while wellmarketed products of equivocal value achieve widespread adoption. Should policymakers attempt to influence clinical behavior and correct for these inefficiencies? Implementation methods achieve a certain level of behavioral change but cost money to enact. These factors can be combined with the cost-effectiveness of treatments to estimate an overall policy costeffectiveness. In general, policy cost-effectiveness is always less attractive than treatment cost-effectiveness. Consequently trying to improve the uptake of underused cost-effective care or reduce the overuse of new and expensive treatments may not always make economic sense. In this article, we present a method for calculating policy cost-effectiveness and illustrate it with examples from a recent trial, conducted during 1997 and 1998, of educational outreach by community pharmacists to influence physician prescribing in England.

JAMA. 2001;286:2988-2992

www.jama.com

ing studied the profile of costs, benefits, and harms for these conditions, have recommended that physicians should address these shortcomings. The recommendations feature different economic messages. Every patient with depression treated first-line with a selective serotonin reuptake inhibitor (SSRI) instead of a tricyclic antidepressant costs an additional $\$ 75$ per episode without demonstrable clinical benefit. ${ }^{6}$ Patients with heart failure not treated with an ACE inhibitor are denied a costeffective treatment, ${ }^{7}$ valued at $\$ 2156$ per life-year gained. ${ }^{8}$ Costings, originally conducted in pounds sterling, have been converted to US dollars $(£ 1=\$ 1.50)$ for ease of exposition.

\section{The Economics of Behavioral Change}

A health policymaker may suspect many instances of suboptimal care but what, and how much, can be done about it?
The answer depends upon a number of steps (FIGURE). Implementation requires a clear and deliverable evidencebased message, evidence that current care is suboptimal and the message is not being applied, a robust estimate of the cost and impact of alternative methods of behavioral change, and understanding of the local organization of health care. ${ }^{9}$ With information at each step, a policymaker is able to understand the likely costs and health consequences of

Author Affiliations: Centre for Health Services Research, University of Newcastle Upon Tyne (Drs Mason and Eccles); Department of Primary Care and General Practice, University of Birmingham, Edgbaston (Dr Freemantle); Department of Primary Care and Population Sciences, Royal Free and University College Medical School, London (Dr Nazareth); London School of Hygiene and Tropical Medicine, London (Dr Haines); and Centre for Health Economics, University of York (Dr Drummond), England.

Corresponding Author and Reprints: James Mason, DPhil, Centre for Health Services Research, University of Newcastle Upon Tyne, 21 Claremont PI, Newcastle Upon Tyne, NE2 4AA, England (e-mail: james .mason@ncl.ac.uk). 
intervening in instances of suboptimal care.

The costs and benefits of influencing physician behavior are derived in the Box. This presentation shows that having to invest resources to change physician behavior imposes an addition, or loading factor, upon treatment costeffectiveness. It is transparent that policy cost-effectiveness is likely to remain attractive in those treatments that are highly cost-effective and likely to become unattractive when cost-effectiveness of treatment is borderline at the outset. In general, whether implementation by any given method is worthwhile involves a complex interplay of factors. Cheaper implementation methods achieving greater levels of change reduce the loading effect. Similarly, larger health gains per patient, higher prevalence of disease, larger practice size, or longer duration of behavioral change all reduce the loading, all other things being equal. When the loading is small, treatment and policy cost-effectiveness are very similar. When the loading is large, a cost-effective treatment may not be worthwhile pursuing as a policy goal, using behavioral change methods.

Some treatment decisions involve selection between alternatives with equivalent outcomes. The policy decision to influence behavior then centers on cost alone. The decision rule simplifies to one where the overall costsaving from changed patterns of health care must exceed the overall cost of implementation.

\section{Educational Outreach}

Educational outreach visits by pharmacists to primary care physicians is one method to promote changes in prescribing medications. A recent randomized controlled trial of Evidence-Based OutReach (EBOR) explored the impact of this method, incorporating recommendations for the use of ACE inhibitors and antidepressants. ${ }^{10,11}$ Data on 11328 patients were collected from 162 general practitioners in 69 practices.

In England, the National Health Service is divided for administration purposes into local Health Authorities with
Figure. Flow Diagram of Steps Involved in the Decision to Influence Professional Behavior

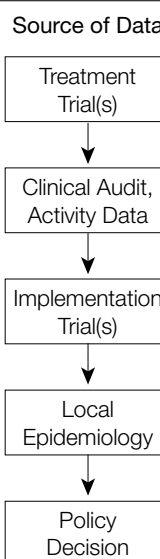

$$
\text { Steps }
$$

Summary of Evidence for Treatment

Net cost and health gain from treatment per patient

Local Evidence of Suboptimal Care

Scope to obtain better value-for-money from health service resources

Summary of Evidence for Implementation

Net cost of implementation per practice and additional patient care

following guidance for each method of behavioral change considered

Local Implementation Scale Factors

The number of practices and patients covered by implementation

Policy Costs and Benefits of Influencing Clinician Behavior (see Box)

\section{Box. Derivation of Policy Cost-effectiveness}

\section{Summary of Evidence for Treatment (Cost-effectiveness)}

$\Delta c_{\mathrm{t}}=$ net cost of care per additional patient treated $\Delta \mathrm{b}_{\mathrm{t}}=$ health gain per additional patient treated $\Delta \mathrm{CE}_{\mathrm{t}}=$ treatment cost-effectiveness, $\Delta \mathrm{c}_{\mathrm{t}} / \Delta \mathrm{b}_{\mathrm{t}}$

\section{Summary of Evidence for Implementation}

$\Delta \mathrm{c}_{\mathrm{i}}=$ net cost of implementing change per practice

$\Delta \mathrm{b}_{\mathrm{i}}=$ change in proportion of patient care following guidance

$\Delta \mathrm{CE}_{\mathrm{i}}=$ implementation cost-effectiveness, $\Delta \mathrm{c}_{\mathrm{i}} / \Delta \mathrm{b}_{\mathrm{i}}$

\section{Local Implementation Scale Factors}

$\mathrm{n}=$ the number of practices (or hospitals) involved

$\mathrm{N}=$ the number of patients targeted

Net policy cost: $\Delta \mathrm{C}_{\mathrm{p}}=\Delta \mathrm{c}_{\mathrm{i}} \times \mathrm{n}+\Delta \mathrm{b}_{\mathrm{i}} \times \mathrm{N} \times \Delta \mathrm{c}_{\mathrm{t}}$

Net policy benefit: $\Delta \mathrm{B}_{\mathrm{p}}=\Delta \mathrm{b}_{\mathrm{i}} \times \mathrm{N} \times \Delta \mathrm{b}_{\mathrm{t}}$

\section{Policy Decision (Cost-effectiveness)}

Policy cost-effectiveness:

$$
\Delta C E_{p}=\frac{\Delta c_{i} \times n+\Delta b_{i} \times N \times \Delta c_{t}}{\Delta b_{i} \times N \times \Delta b_{t}}=\frac{n}{N \times \Delta b_{t}} \times \Delta C_{i}+\Delta C E_{t}
$$

$\mathrm{N} / \mathrm{n}$, the number of patients per practice targeted by the guidance, depends on the prevalence of the condition being targeted and the length of time over which behavior continues to be influenced

$\mathrm{n}_{\mathrm{p}}=$ the average practice size

$\mathrm{p}_{\mathrm{d}}=$ population prevalence of the condition targeted

$\mathrm{d}=$ duration of effect

Then, policy cost-effectiveness:

$$
\Delta \mathrm{CE}_{\mathrm{p}}=\frac{1}{\mathrm{~d} \times \mathrm{n}_{\mathrm{p}} \times \mathrm{p}_{\mathrm{d}} \times \Delta \mathrm{b}_{\mathrm{t}}} \times \Delta \mathrm{CE}_{\mathrm{i}}+\Delta \mathrm{CE}_{\mathrm{t}}=\mathrm{L}_{\mathrm{CE}}+\Delta \mathrm{CE}_{\mathrm{t}}
$$

where $\mathrm{L}_{\mathrm{CE}}$ is the loading factor upon treatment cost-effectiveness

Policy Decision (Cost-minimization)

Policy cost: $\Delta \mathrm{C}_{\mathrm{p}}=\Delta \mathrm{C}_{\mathrm{i}}+\Delta \mathrm{C}_{\mathrm{t}}=\Delta \mathrm{c}_{\mathrm{i}} \times \mathrm{n}+\Delta \mathrm{b}_{\mathrm{i}} \times \mathrm{N} \times \Delta \mathrm{c}_{\mathrm{t}}$

Cost saving requires $\Delta \mathrm{C}_{\mathrm{p}}<0$, thus:

$$
-\Delta \mathrm{C}_{\mathrm{t}}>\Delta \mathrm{C}_{\mathrm{i}} \text { or }-\Delta \mathrm{c}_{\mathrm{t}}>\frac{1}{\mathrm{~d} \times \mathrm{n}_{\mathrm{p}} \times \mathrm{p}_{\mathrm{d}} \times \Delta \mathrm{b}_{\mathrm{i}}} \times \Delta \mathrm{c}_{\mathrm{i}} \text { or }-\Delta \mathrm{c}_{\mathrm{t}}>\mathrm{L}_{\mathrm{C}} \times \Delta \mathrm{c}_{\mathrm{i}}
$$


an average population of about half a million. Primary health care is provided by general practitioners who organize themselves into practices of vary- ing size, but with an average of 3 to 4 practitioners and about 6000 registered patients. Overall, outreach had a significant effect measured as the change

\begin{tabular}{|c|c|c|}
\hline & $\begin{array}{l}\text { Evidence-Based OutReach } \\
\text { (EBOR) Study }\end{array}$ & $\begin{array}{c}\text { Health } \\
\text { Authority (HA) }\end{array}$ \\
\hline \multicolumn{2}{|l|}{ Scale factors, No. } & 90 \\
\hline Patients* & $\ldots$ & 514080 \\
\hline Practices receiving outreach $†$ & 75 & 63 \\
\hline $\begin{array}{l}\text { Patients in practices with } \\
\text { outreach* }\end{array}$ & $\cdots$ & 360340 \\
\hline Guidelines per practice $\ddagger$ & 2 & 1 \\
\hline $\begin{array}{l}\text { Costs, } \$ \\
\quad \text { Guideline materials }\end{array}$ & 5550 & 2340 \\
\hline Training and recruiting staff & 4830 & 2040 \\
\hline Training facilities hire & 5430 & 2295 \\
\hline Implementation coordinator & 33225 & 14025 \\
\hline Pharmacist training§ & 10185 & 4305 \\
\hline Pharmacist outreach§ & 31725 & 13395 \\
\hline Total $(2000$ costs)\| & 90945 & 38400 \\
\hline \multicolumn{3}{|c|}{$\begin{array}{l}\text { *In England in 1999, there were } 50.9 \text { million registered patients in } 99 \mathrm{HAs} \text { and } 8944 \text { General Practice Partnerships. }{ }^{12} \\
\text { These data are used to calculate the average number of patients and practices per HA. From these data, the aver- } \\
\text { age general practice list size is } 5960 \text { patients. Ellipses indicate number of patients in EBOR study is not known. } \\
\text { +The EBOR trial featured } 70 \% \text { compliance with the request to provide the intervention. } \\
\text { fln the EBOR trial, } 12 \text { pharmacists each delivered } 2 \text { of } 4 \text { guidelines to } 75 \text { practices. } \\
\text { \$Pharmacists were employed at a locum rate }(\$ 22.50 / \text { hour) to cover time training, preparation, traveling, and deliver- } \\
\text { ing the intervention; this rate reflects salary and on-costs. Travel costs are also included. }\end{array}$} \\
\hline
\end{tabular}

in adherence to guideline recommendations across the guideline topics (odds ratio [OR], 1.2; 95\% confidence inter$\operatorname{val}(\mathrm{CI}), 1.1-1.4)$. Applying this OR to a baseline adherence rate of $40 \%$, there is a $5.2 \%(95 \% \mathrm{CI}, 1.7 \%-8.7 \%)$ increase in the number of patients treated according to the recommendations. Small practices (with 1 or 2 practitioners) demonstrated a substantially greater response to outreach than larger practices. Consequently, adherence in smaller practices improved by $13.5 \%$ (95\% CI, 6.0\%-20.9\%) from a baseline adherence rate of $40 \%$.

\section{Cost-effectiveness of Educational Outreach}

Based on the use of resources in the EBOR trial, a similar willingness to receive outreach, and absence of scale effects, outreach for 1 guideline is estimated to cost $\$ 38400$ per Health Authority (TABLE 1).

The policy cost-effectiveness for the 2 examples using educational outreach is summarized in TABLE 2 . The cost per guideline per practice per unit

Table 2. Cost-effectiveness of a Policy of Delivering Educational Outreach Using Community Pharmacists*

\begin{tabular}{|c|c|c|c|c|}
\hline & \multicolumn{2}{|c|}{ All Practices } & \multicolumn{2}{|c|}{ Small Practices $\dagger$} \\
\hline & ACE Inhibitors & SSRIs & ACE Inhibitors & SSRIs \\
\hline \multicolumn{5}{|l|}{ Treatment } \\
\hline Cost of treatment per patient, $\$, \Delta c_{t}$ & 1035 & -75 & 1035 & -75 \\
\hline Effect of treatment per patient, LY, $\Delta \mathrm{b}_{\mathrm{t}}$ & $0.48(0.30-0.64)$ & 0 & $0.48(0.30-0.64)$ & 0 \\
\hline Cost-effectiveness of treatment, $\$ / L Y, \Delta \mathrm{CE}_{t}$ & $2156(1617-3450)$ & NA & $2156(1617-3450)$ & NA \\
\hline \multicolumn{4}{|l|}{ Educational outreach } & $13.5 \%(6.0 \%-20.9 \%)$ \\
\hline Cost per practice per guideline, $\$, \Delta \mathrm{c}_{\mathrm{i}}$ & 608 & 608 & 608 & 608 \\
\hline $\begin{array}{l}\text { Cost-effectiveness of implementation, } \Delta \mathrm{CE}_{\mathrm{i}} \\
\text { (\$/unit change in behavior/guideline/practice) }\end{array}$ & $11690(6980-35740)$ & $11690(6980-35740)$ & $4500(2910-10130)$ & $4500(2910-10130)$ \\
\hline \multicolumn{5}{|l|}{ Implementation by Health Authority§ } \\
\hline Loading $\mathrm{L}_{\mathrm{CE}}, \$ / \mathrm{LY}$ & $446(200-2181)$ & NA & $379(183-1363)$ & NA \\
\hline $\mathrm{L}_{\mathrm{c}} \times \Delta \mathrm{c}_{\mathrm{i}}, \$$ & NA & $82(49-251)$ & NA & $70(45-157)$ \\
\hline \multicolumn{4}{|l|}{ Policy evaluation } & NA \\
\hline Net cost per extra patient treated\# & NA & $7(-26$ to 176$)$ & NA & $-5(-30$ to 82$)$ \\
\hline \multicolumn{5}{|c|}{$\begin{array}{l}\text { *LY indicates life-years gained; ACE, angiotensin-converting enzyme; SSRI, selective serotonin reuptake inhibitor. } 95 \% \text { confidence intervals are shown in parentheses. The lower } \\
\text { (higher) estimates of both health benefit and behavioral change are combined to give approximate lower (higher) estimates for net policy cost, benefit, and cost-effectiveness. See } \\
\text { the Box for definitions of formulas. NA indicates no data are appropriate. } \\
\text { tPractices with } 1 \text { or } 2 \text { general practitioners. } \\
\text { fThe average level of change across all guideline topics is taken as the best estimate of behavioral change achievable by the educational outreach method. The EBOR trial was not } \\
\text { powered to detect differences in levels of change between guideline topics. } \\
\text { \$The practice list size }\left(\mathrm{n}_{\mathrm{p}} \text { ) for all practices is } 5690 \text { and for small practices is } 2580 \text {. The duration of behavioral change for both practices was } 1 \text { year. }\right. \\
\| \text { The population prevalence for heart failure is derived from a national survey of general practice activity. }{ }^{13} \text { The estimate for depression is derived from the annual volume of drug use } \\
\text { reported in the guideline, }{ }^{6} \text { since it is the change in this population being targeted. } \\
\text { ISee Formula } 2 \text { in the Box. } \\
\text { \#See Formula } 3 \text { in the Box. }\end{array}$} \\
\hline
\end{tabular}


change in behavior $\left(\Delta C E_{\mathrm{i}}\right)$ is $\$ 11690$ (95\% CI, \$6980-\$35740). The effect of the implementation loading (\$446/lifeyear gained) upon the treatment costeffectiveness of ACE inhibitors (\$2156/ life-year gained) for heart failure is small and a policy of implementation is costeffective (\$2602/life-year gained). Academic outreach to promote a reduction in use of SSRIs in favor of tricyclic antidepressants is not estimated to be cost-saving: the cost per patient of outreach (\$82) exceeds the cost-saving from behavioral change ( $\$ 75)$. This would not be worth pursuing by educational outreach.

The impact of educational outreach on small practices ( 1 or 2 partners) is modeled as a subgroup analysis (Table 2). Although an increase in outreach effectiveness $\left(\Delta b_{\mathrm{i}}\right)$ reduces the loading factor, this is partially offset by a reduction in numbers of patients per practice targeted by each guideline. Nonetheless, intervention to reduce the use of SSRIs has become cost-saving, although the magnitude of saving is imprecise.

\section{Using the Framework}

As with any model, a number of assumptions are necessary. Local patients are assumed typical of those enrolled in trials and are treated to the same extent. That is, patients treated are being counted rather than the amount of treatment received by each patient. The findings of the implementation studies may have to be assumed transferable not just to different localities but with different evidence-based messages and diseases. As with the costs of treatments, the costs of outreach may be anticipated to vary by locality and country. Implementation studies that report units of component resources, disaggregated from their unit costs, will help users derive a valid local cost of implementation by applying local patterns of resource use and prices. Economies of scale may be important since each guideline has fixed training costs but may be implemented on a varying number of practices.

The effect of time on the magnitude of behavioral change achieved by implementation methods is uncertain. It is unlikely that change is constant in magnitude or permanent. A recent evaluation of a computer-based clinical decision support system to prevent venous thromboembolism highlighted the need for continuing implementation of the system to achieve lasting behavioral change. ${ }^{14}$ In the EBOR trial, measures of adherence to guidelines were made at baseline and after 12 months with intervention occurring between 3 and 6 months. For simplicity it has been assumed that outreach has an effect for 1 year and then ceases, at which time further outreach activity is required. This is analogous to assuming a full effect for the first 6 months reduced by $50 \%$ every subsequent 6 months.

The perspective in our illustration is a local policymaker faced with the decision to implement national guidelines. The principal costs associated with outreach visits are for the salaries of the outreach workers and their facilitators (Table 1). There are also costs associated with the recruitment of outreach workers, training, and the development and production of local promotional materials. In these examples, the cost of guideline development has been explicitly excluded, because in England and Wales, there is a commitment to produce evidence-based guidelines and related audit measures; from the perspective of the analysis, the guidelines are free goods. Similarly, physicians are expected to undergo continuing education and audit; time participating in these activities has not been charged. Other assumptions are possible as necessary for particular situations.

\section{COMMENT}

Health systems experience considerable pressure to provide new health technologies, sometimes of borderline costeffectiveness, while long-established, cheap, and effective but unfashionable health care may not be used. The model we present shows that multiple influences determine whether investing to achieve behavioral change is worthwhile. The preconditions are that there is an evidence-based message of acceptable clinical and cost-effective care, and current care is suboptimal. Worthwhile behavioral change from a policy viewpoint requires an implementation method that does not load treatment cost-effectiveness to such an extent that normal bounds of cost-effectiveness are exceeded.

In the main analysis, the costeffectiveness message (ACE inhibitors) was worth implementing but the cost-saving message (antidepressant selection) was not. The large health benefit achieved by ACE inhibitors used in heart failure favorably influenced both treatment cost-effectiveness and the loading term. Changing the choice of antidepressant for depression achieves small cost-savings that do not exceed the cost of the implementation method. The promotion of interventions to reduce mortality or major morbidity is more likely to prove attractive than those switching prescriptions from a more expensive to a less costly pharmaceutical. The relatively high cost of influencing prescriptions can quickly overwhelm potential cost-savings.

We have presented a method to help decision makers explore whether investing in change is worthwhile. This may be applied in any currency and for any unit of outcome, and is valid when investing to reduce as well as increase activity. Although educational outreach visits to primary care physicians by pharmacists are a popular strategy, their impact is modest. As more implementation strategies are evaluated for their cost and level of behavorial change, it should be possible for any condition with known prevalence to estimate loading adjustments for treatment cost-effectiveness, and thus to determine the best implementation method to meet policy goals.

Author Contributions: Study concept and design: Mason, Freemantle, Haines, Drummond. Acquisition of data: Mason, Freemantle, Nazareth. Analysis and interpretation of data: Mason, Freemantle, Eccles, Drummond.

Drafting of the manuscript: Mason, Freemantle, Haines. Critical revision of the manuscript for important intellectual content: Mason, Freemantle, Nazareth, Eccles, Haines, Drummond.

Statistical expertise: Mason, Freemantle. Obtained funding: Freemantle, Eccles, Haines. Administrative, technical, or material support: Mason, Freemantle, Nazareth, Drummond. 
Study supervision: Freemantle, Nazareth, Eccles, Drummond.

Funding/Support: The Evidence-Based OutReach (EBOR) trial and our subsequent analysis were funded by the Department of Health Policy-Related Programme of Research and Development, Skipton House, London, England.

Disclaimer: The views expressed are those of the authors and not necessarily those of the Department of Health.

\section{REFERENCES}

1. Antman EM, Lau J, Kupelnick B, Mosteller F, Chalmers TC. A comparison of results of meta-analyses of randomized control trials and recommendations of clinical experts. JAMA. 1992;268:240-248.

2. Effective Health Care. Implementing Clinical Practice Guidelines. Leeds, England: University of Leeds; 1994. Bulletin No. 8

3. Freemantle N, Harvey E, Grimshaw J, et al. The effectiveness of printed educational materials in changing the behaviour of healthcare professionals. In: Freemantle N, Bero L, Grilli R, Grimshaw J, Oxman A, eds. Effective Professional Practice Module. Oxford,
England: The Cochrane Database of Systematic Reviews; 1996:issue 3.

4. Freemantle N, Mason JM. Is all publicity good publicity? a review of the Prozac years. Pharmacoeconomics. 2000;17:319-324.

5. Mason J, Young P, Freemantle N, Hobbs R. Safety and costs of initiating angiotensin converting enzyme inhibitors for heart failure in primary care: analysis of individual patient data from studies of left ventricular dysfunction. BMJ. 2000;321:1113-1116. 6. Eccles M, Freemantle N, Mason JM. North of England Evidence-Based Guideline Development project: summary version of guidelines for the choice of antidepressants for depression in primary care. Fam Pract. 1999;16:103-111.

7. Eccles M, Freemantle N, Mason JM. North of England Evidence-Based Guideline Development project: guideline for angiotensin converting enzyme inhibitors in primary care management of adults with symptomatic heart failure. BMJ. 1998:316:1369-1375

8. National Electronic Library for Health: Clinical Guidelines Database. North of England Evidence-Based Guideline Development Project. Primary care management of secondary prophylaxis for patients who have experienced a myocardial infarction: drug treatment, cardiac rehabilitation and dietary manipulation. Available at: http://www.nelh.nhs.uk/guidelines database.asp. Accessibility verified October 30, 2001.

9. Mason JM, Wood J, Freemantle N. Designing evaluations of interventions to change professional practice [correction appears in J Health Serv Res Policy. 1999; 4:192]. J Health Serv Res Policy. 1999;4:106-111. 10. Freemantle $N$, Eccles $M$, Wood J, et al. A randomised trial of Evidence-based OutReach (EBOR): rationale and design. Control Clin Trials. 1999;20: 479-492.

11. Freemantle $N$, Nazareth I, Eccles $M$, et al. A randomised trial of the effect of educational outreach by community pharmacists on prescribing in primary care. Br J Gen Pract. In press.

12. Birmingham R. General and Personal Medical Statistics, England and Wales, 1 October 1999. Leeds, England: NHS Executive; 2000.

13. OPCS Monitor: Morbidity Statistics From Gen eral Practice 1991/1992. London, England: OPCS 1995.

14. Durieux $P$, Nizard R, Ravaud $P$, Mounier N, Lepage $E$. A clinical decision support system for prevention of venous thromboembolism: effect on physician behavior. JAMA. 2000;283:2816-2821. 